\title{
Involvement of the anterior cingulate cortex in formation, consolidation, and reconsolidation of recent and remote contextual fear memory
}

\author{
Einar Ö. Einarsson ${ }^{1,2}$ and Karim Nader ${ }^{1,3}$ \\ ${ }^{1}$ Department of Psychology, McGill University, Montreal, Quebec, Canada, H3A 1B1; ${ }^{2}$ INSERM U862, Neurocentre Magendie, 33077 \\ Bordeaux, France
}

\begin{abstract}
It has been suggested that memories become more stable and less susceptible to the disruption of reconsolidation over weeks after learning. Here, we test this by targeting the anterior cingulate cortex (ACC) and test its involvement in the formation, consolidation, and reconsolidation of recent and remote contextual fear memory. We found that inhibiting NMDARNR2B activity disrupts memory formation, and that infusion of the protein-synthesis inhibitor anisomycin impairs memory consolidation and reconsolidation of recent and remote memory. Our findings demonstrate for the first time that the ACC plays an important role in reconsolidation of contextual fear memory at recent and remote time points.
\end{abstract}

[Supplemental material is available for this article.]

Memory consolidation refers to a hypothetical process of gradual stabilization that new memories must undergo in order to persist (Müller and Pilzecker 1900). Such a process has been studied on two levels of analysis: the cellular level and the brain systems level (Dudai and Morris 2000). The first, cellular consolidation, is thought to be a ubiquitous property in memory formation and involves intracellular signaling cascades involving modulation of gene expression and protein synthesis in localized circuits (Agranoff and Klinger 1964; Davis and Squire 1984; Kandel 2001). This process becomes stabilized within hours after initiation as memories become insensitive to amnesic agents over time (e.g., the protein synthesis inhibitor anisomycin). The second type, systems consolidation, occurs over a much longer time frame, involving gradual changes at the level of brain structures and may last weeks to years depending on the memory system, task, and species involved (Frankland and Bontempi 2005). At this level of analysis, involvement of a brain structure is inferred from behavioral performance following pre-test inactivation of the brain region (permanent or transient). Studies using animal models have described how memories that are initially dependent upon the hippocampus for retrieval become independent of that structure over time, a process hypothesized to reflect neocortical traces becoming sufficiently strong to support retrieval (McClelland et al. 1995). A number of studies have found such a gradient for contextual fear conditioning for the hippocampus, where inactivating the structure impairs recent but not remote memory ( $>14 \mathrm{~d}$ old), suggesting decreased involvement of the structure in memory retrieval over weeks following memory acquisition (Kim and Fanselow 1992; Anagnostaras et al. 1999; Ward et al. 1999; Kitamura et al. 2009; Wiltgen et al. 2010; de Oliveira Alvares et al. 2012; but see Goshen et al. 2011). Conversely, the opposite gradient has been found for the involvement of the ACC where pharmacological inactivation impairs remote memory expression but not recent memory, suggesting increased involvement as the memory ages (Frankland et al. 2004).

\footnotetext{
${ }^{3}$ Corresponding author

E-mail karim.nader@mcgill.ca

Article is online at http://www.learnmem.org/cgi/doi/10.1101/lm.027227.112.
}

Although memories become stabilized following a consolidation phase, retrieval can return memories to a sensitive state once more following retrieval, both on a cellular (e.g., renewed sensitivity to protein synthesis inhibitors) (Nader et al. 2000) and systems level (e.g., renewed sensitivity to hippocampal inactivation) (Debiec et al. 2002). This process of reconsolidation has been demonstrated across species, memory paradigms, and with various behavioral and pharmacological methods (for review, see Nader and Einarsson 2010). Reconsolidation does not seem to occur every time a memory is retrieved, and it has been suggested that as memory ages it can become more stable and less susceptible to pharmacological disruption following retrieval (Dudai and Eisenberg 2004). Two studies using mice found that systemic infusions of anisomycin that were effective in impairing recent contextual fear memory ( $1 \mathrm{~d}$ old $)$ were ineffective for older memories ( $>1$ mo old) (Suzuki et al. 2004; Frankland et al. 2006). However, if the duration of the retrieval sessions were prolonged, both studies found that the treatment once again disrupted the memory. In one of the two studies, anisomycin was also infused locally into either the hippocampus or the ACC of mice immediately following retrieval of either a recent or remote memory (Frankland et al. 2006). The study found that intrahippocampal infusions impaired recent, but not remote, memory, while intra-ACC infusions had no effect on either recent or remote memory expression. In contrast, an earlier study examining contextual fear memory in rats found that anisomycin infusions into the hippocampus impaired both recent and remote memory (Debiec et al. 2002), suggesting that the memory continues to be sensitive to hippocampal reconsolidation challenges over time. Moreover, studies have found that the ACC plays a key role in the formation and consolidation of contextual fear memory, both in mice (Zhao et al. 2005; Vetere et al. 2011) and rats (Zhao et al. 2005), indicating a prominent role in stabilizing a new memory.

Here we target the ACC and test its involvement in the formation, cellular consolidation, and reconsolidation of recent and remote contextual fear memory in rats. We examine the involvement of the structure in memory formation by pharmacologically blocking NMDA-NR2B subunit activity before training, test 
cellular consolidation by infusing the protein-synthesis inhibitor anisomycin immediately following conditioning, and reconsolidation by infusing anisomycin immediately after memory reactivation in separate experiments at 3-d and 30-d post-training (see Supplemental Methods for details, and Supplemental Fig. 1 for cannula placements of all experiments).

In testing whether the ACC contributes to the formation of contextual fear memory, we infused the NMDA receptor NR2B subunit antagonist Ro25-6981 immediately before contextual fear conditioning with eight unsignaled footshocks. When tested 3 d later, animals receiving Ro25-6981 showed significantly lower freezing than animals receiving the saline vehicle infusions $\left(t_{(12)}=2.5, P<0.05\right)$ (Fig. 1A). These findings are in line with previous findings that NMDA-NR2B subunit activity in the ACC is critical for the acquisition of one footshock-conditioning contextual fear memory in the ACC (Zhao et al. 2005).

In order to test whether the ACC is involved in cellular consolidation of contextual fear memory, we infused the protein synthesis inhibitor anisomycin immediately following conditioning. While anisomycin, a broad-spectrum translation inhibitor, is thought to produce its amnesic effects via inhibition of protein synthesis, it has recently been suggested to also work by changing neurotransmitter levels (Canal et al. 2007). For our purposes, the exact mechanism by which anisomycin induces amnesia is not important, but rather whether it can impair cellular consolidation and reconsolidation in the ACC, as it has been found to do in other brain structures (Nader and Hardt 2009). Rats infused with anisomycin immediately after conditioning showed no impairment compared with vehicle-infused animals when tested $4 \mathrm{~h}$ later for short-term memory (STM), whereas when tested a day later for long-term memory (LTM), they showed a reduction in freezing (drug $\times$ memory test interaction $F_{(1,13)}=7.07, P<0.05$; post hoc STM-test, $P>0.05$, post hoc LTM-test, $P<0.05$ ) (Fig. 1B). This suggests that the ACC is involved in the cellular consolidation of contextual fear memories.

To test the involvement of the ACC in cellular reconsolidation of recent memories, animals were re-exposed to the conditioning context for memory reactivation $3 \mathrm{~d}$ after training for $90 \mathrm{sec}$, followed by intra-ACC infusions of anisomycin or its vehicle. Anisomycin and vehicle groups exhibited similar levels of freezing during reactivation $\left(t_{(17)}<1\right)$ (Fig. 2A). Repeated measures ANOVA

showed a significant drug $\times$ memory test interaction $\left(F_{(1,17)}=\right.$ $19.5, P<0.001)$. Post hoc comparison showed similar freezing during the PR-STM test $(P>0.05)$, but impaired freezing by the anisomycin group compared with the vehicle group on the PR-LTM test $(P<0.05)$. This suggests that the ACC is involved in the cellular reconsolidation of 3-d-old contextual fear memory.

To examine cellular reconsolidation of remote memory in the ACC we re-exposed animals to the conditioning context $30 \mathrm{~d}$ after training using the same protocol as above. Vehicle and anisomycin groups demonstrated equivalent freezing during reactivation $\left(t_{(20)}<1\right)$ (Fig. 2B). A repeated-measures ANOVA comparing drug (anisomycin vs. vehicle) with memory test (PR-STMvs. PR-LTM) revealed a significant interaction $\left(F_{(1,20)}=6.49, P<0.05\right)$. Post hoc comparisons showed that on the PR-STM test, both groups were again comparable $(P>0.05)$, while on the PR-LTM test, the anisomycin-treated animals were significantly impaired compared with the vehicle group $(P<0.05)$, consistent with a reconsolidation impairment. Similar infusions without a reactivation trial at $30 \mathrm{~d}$ did not cause any memory impairment when tested 4 and 24 h later (drug $\times$ test interaction: $F_{(1,8)}<1, P>0.05$ ) (Fig. $2 \mathrm{C}$ ). Thus, the sensitivity of the memory trace to anisomycin was predicated on memory reactivation. To test for anatomical specificity of the effects of infusion into the ACC, a separate group received anisomycin infusions into the adjacent primary/secondary motor cortex following a reactivation trial $30 \mathrm{~d}$ after training. During reactivation both groups showed comparable freezing $\left(t_{(15)}<0\right)$ (Fig. 2D) and similarly showed no difference at PR-STM and PR-LTM testing (drug $\times$ memory test interaction: $F_{(1,15)}=0.22, P>0.05$ ), suggesting that the effects of anisomycin infused into the ACC were not due to lateral diffusion into these neighboring areas.

Our data demonstrate that the circuits supporting contextual fear memory involve the ACC from the formation of the memory as pretraining pharmacological inhibition of NMDAR-NR2B subunit activity in the structure impairs memory acquisition, consistent with previous findings (Zhao et al. 2005). Similarly, local infusions of the protein-synthesis inhibitor anisomycin immediately following conditioning lead to delayed memory impairments, suggesting that contextual fear memory undergoes cellular consolidation in the ACC.

Previous studies have shown that contextual fear memory can undergo cellular reconsolidation in the dorsal hippocampus following retrieval at recent (Debiec et al. 2002; Frankland et al. 2006; Lee 2008; Lee et al. 2008) and remote (Debiec et al.

A
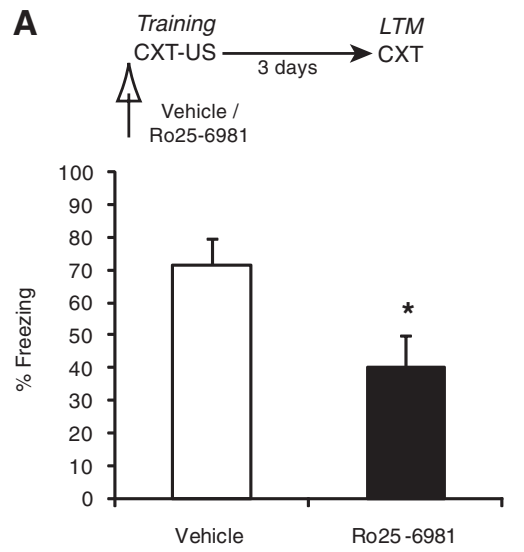

Figure 1. The involvement of the $A C C$ in the acquisition and cellular consolidation of contextual fear memory. (A) Animals receiving ACC infusions of the NR2B subunit antagonist Ro25-6981 $(n=7)$ before conditioning showed impaired levels of freezing relative to the vehicle control group $(n=7)$ when tested 3 d later. $(B)$ Animals receiving anisomycin $(n=8)$ infusions immediately after conditioning showed similar freezing to those receiving vehicle $(n=7) 4 \mathrm{~h}$ later (STM test), whereas at $24 \mathrm{~h}$ after conditioning, anisomycin animals showed impaired freezing (LTM test), suggesting impaired memory consolidation. (*) $P<0.05$ compared with vehicle group. Data presented as group means \pm SEM.
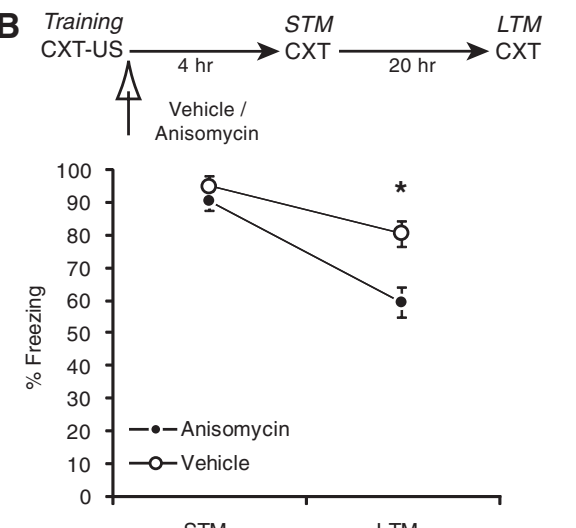

time points. Here we present the first demonstration that such memory undergoes anisomycin-sensitive cellular reconsolidation in the ACC, at both recent and remote time points. Similar post-retrieval infusions in the primary/ secondary motor cortex had no effect on later memory expression, suggesting that impairments following infusions into the ACC were not due to lateral diffusion of the drug. Thus, similar to a previous study using the same task and training parameters, but focusing on the dorsal hippocampus (Debiec et al. 2002), we find that anisomycin infusions into the ACC following retrieval of recent and remote memory leads to ungraded retrograde amnesia. Contrary to our findings, Frankland et al. (2006) did not find any evidence of recent or remote contextual fear memory undergoing cellular reconsolidation in the ACC in mice and, 
A
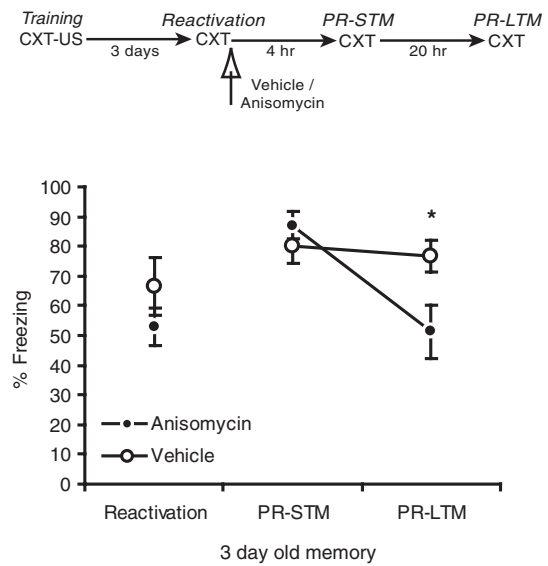

C
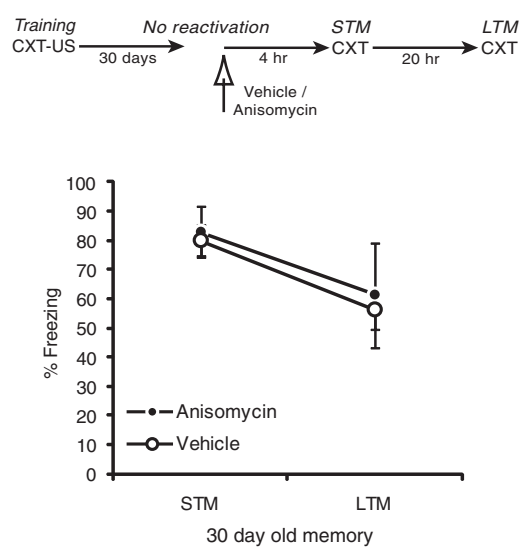

B
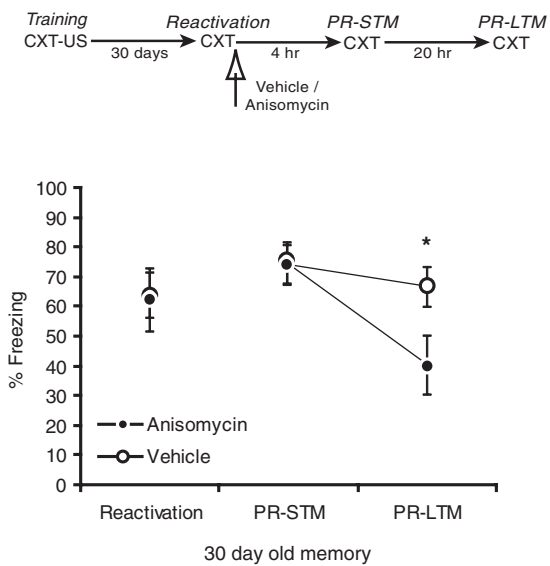

D
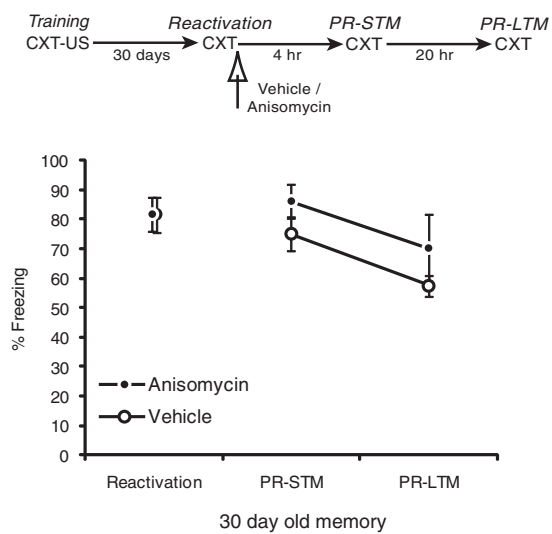

Figure 2. ACC involvement in cellular reconsolidation: infusions of anisomycin following memory reactivation impair 3-d and 30-d-old contextual fear memory. (A) Animals received intra-ACC infusions of anisomycin $(n=9)$ or its vehicle $(n=10)$ immediately after memory reactivation $3 \mathrm{~d}$ after conditioning. Both groups showed similar levels of freezing $4 \mathrm{~h}$ later (PR-STM test), while at $24 \mathrm{~h}$ the anisomycin group showed impaired memory expression (PR-LTM), indicating a reconsolidation impairment. $(B)$ Post-reactivation intra-ACC infusions $30 \mathrm{~d}$ after training found anisomycin $(n=11)$ and vehicle groups $(n=11)$ to show similar levels of freezing at PR-STM and the anisomycin group with impaired memory expression at PR-LTM, demonstrating a reconsolidation impairment. (C) Intra-ACC infusions of anisomycin $(n=5)$ or its vehicle $(n=5) 30 \mathrm{~d}$ after training in the absence of memory reactivation did not impair memory reconsolidation. (D) Post-reactivation infusions of anisomycin $(n=9)$ or its vehicle $(n=8)$ into the primary/secondary motor cortices which neighbors the ACC $30 \mathrm{~d}$ after training did not impair memory reconsolidation. $\left(^{*}\right) P<0.05$ relative to the vehicle group. Data presented as group means \pm SEM.

similarly, no evidence for dorsal hippocampus involvement in cellular reconsolidation of remote memory, contrary to Debiec et al. (2002), although both studies demonstrated cellular reconsolidation of recent memory in the dorsal hippocampus.

It is possible that the parameters of Frankland et al. (2006) were not adequate to induce cellular reconsolidation, which is known to not occur under certain boundary conditions (Nader and Hardt 2009). For example, the susceptibility of contextual fear memory to systemic pharmacological disruption of reconsolidation has been found to depend on factors such as the strength of training and duration of the reactivation session (Suzuki et al. 2004; Bustos et al. 2009b), as well as how stressed animals are before training (Bustos et al. 2009a).

One notable difference among the studies of Frankland et al. (2006), our study, and Debiec et al. (2002) is different training intensity, with Frankland et al. (2006) using a weaker 3-foot-shock conditioning, whereas our study and Debiec et al. (2002) used a more intense training protocol of 8-foot-shocks. However, this difference is unlikely to account for the different susceptibility to reconsolidation challenges, as other studies systematically testing the effect of conditioning intensity on reconsolidation have found that stronger, and not weaker, training reduces sensitivity to reconsolidation challenges (Suzuki et al. 2004; Wang et al. 2009). Moreover, these findings suggest that contextual fear memory acquired with fewer footshocks would also undergo reconsolidation in the ACC. Similarly, previous findings showing that local ACC infusions of a NMDA-NR2B receptor antagonist impair the formation of 1-shock contextual fear memory (Zhao et al. 2005), and our findings showing the same treatment impairs the formation of an 8-shock contextual fear memory suggest that the ACC is involved in stabilizing both weak and strong contextual fear memory.

With regard to contextual fear memory age, there are conflicting reports on reduced susceptibility to systemic anisomycin infusions, with Suzuki et al. (2004) reporting more resistance but Frankland et al. (2006) finding no more resistance with age. Similarly, conflicting findings have been reported on susceptibility to local dorsal hippocampus infusions being reduced with time-Frankland et al. (2006) finding reduced susceptibility, while Debiec et al. (2002) did not.

Our finding of such pervasive involvement of the ACC in memory processing contrasts with findings of pretest pharmacological inactivation of the ACC showing temporally graded retrograde amnesia (Frankland et al. 2004). This suggests that a brain structure can play an important role in processing a new or retrieved memory despite not being critical for the retrieval of the memory. One function that could be served by having the ACC undergo cellular reconsolidation prior to being required for retrieval might be to allow new information mediated by the hippocampus to be incorporated into the hippocampal-cortical representation, of which retrieval will later be mediated by the neocortical structures (Lesburgueres et al. 2011). Such a putative process would fit well with cognitive-oriented studies of human memory that model memory to be a constructive rather than a reproductive process (Bartlett 1932; Schacter and Addis 2007; Hardt et al. 2010).

\section{Acknowledgments}

This work was supported by grants from the Canadian Institutes of Health Research and the Natural Sciences and Engineering Research Council of Canada (K.N.). 


\section{References}

Agranoff BW, Klinger PD. 1964. Puromycin effect on memory fixation in the goldfish. Science 146: 952-953.

Anagnostaras SG, Maren S, Fanselow MS. 1999. Temporally graded retrograde amnesia of contextual fear after hippocampal damage in rats: within-subjects examination. I Neurosci 19: 1106-1114.

Bartlett FC. 1932. Remembering. Cambridge University Press, Cambridge, UK.

Bustos SG, Giachero M, Maldonado H, Molina VA. 2009a. Previous stress attenuates the susceptibility to midazolam's disruptive effect on fear memory reconsolidation: Influence of pre-reactivation D-Cycloserine administration. Neuropsychopharmacology 35: 1097-1108.

Bustos SG, Maldonado H, Molina VA. 2009b. Disruptive effect of midazolam on fear memory reconsolidation: decisive influence of reactivation time span and memory age. Neuropsychopharmacology 34: 446-457.

Canal CE, Chang Q, Gold PE. 2007. Amnesia produced by altered release of neurotransmitters after intraamygdala injections of a protein synthesis inhibitor. Proc Natl Acad Sci 104: 12500-12505.

Davis HP, Squire LR. 1984. Protein synthesis and memory: a review. Psychol Bull 96: 518-559.

de Oliveira Alvares L, Einarsson EO, Santana F, Crestani AP, Haubrich J, Cassini LF, Nader K, Quillfeldt JA. 2012. Periodically reactivated context memory retains its precision and dependence on the hippocampus. Hippocampus 22: 1092-1095.

Debiec J, LeDoux JE, Nader K. 2002. Cellular and systems reconsolidation in the hippocampus. Neuron 36: 527-538.

Dudai Y, Eisenberg M. 2004. Rites of passage of the engram: reconsolidation and the lingering consolidation hypothesis. Neuron 44: 93-100.

Dudai Y, Morris R. 2000. To consolidate or not to consolidate: what are the questions? In Brain, percepeption, memory advances in cognitive sciences (ed. J Bolhuis), pp. 149-162. Oxford University Press, Oxford, UK.

Frankland PW, Bontempi B. 2005. The organization of recent and remote memories. Nat Rev 6: 119-130.

Frankland PW, Bontempi B, Talton LE, Kaczmarek L, Silva AJ. 2004. The involvement of the anterior cingulate cortex in remote contextual fear memory. Science 304: $881-883$.

Frankland PW, Ding HK, Takahashi E, Suzuki A, Kida S, Silva AJ. 2006. Stability of recent and remote contextual fear memory. Learn Mem 13: $451-457$.

Goshen I, Brodsky M, Prakash R, Wallace J, Gradinaru V, Ramakrishnan C, Deisseroth K. 2011. Dynamics of retrieval strategies for remote memories. Cell 147: 678-689.

Hardt O, Einarsson EO, Nader K. 2010. A bridge over troubled water: reconsolidation as a link between cognitive and neuroscientific memory research traditions. Annu Rev Psychol 61: 141-167.

Kandel ER. 2001. The molecular biology of memory storage: a dialogue between genes and synapses. Science 294: 1030-1038.

Kim JJ, Fanselow MS. 1992. Modality-specific retrograde amnesia of fear. Science 256: 675-677.
Kitamura T, Saitoh Y, Takashima N, Murayama A, Niibori Y, Ageta H, Sekiguchi M, Sugiyama H, Inokuchi K. 2009. Adult neurogenesis modulates the hippocampus-dependent period of associative fear memory. Cell 139: 814-827.

Lee JL. 2008. Memory reconsolidation mediates the strengthening of memories by additional learning. Nat Neurosci 11: 1264-1266.

Lee SH, Choi JH, Lee N, Lee HR, Kim JI, Yu NK, Choi SL, Lee SH, Kim H, Kaang BK. 2008. Synaptic protein degradation underlies destabilization of retrieved fear memory. Science 319: 1253-1256.

Lesburgueres E, Gobbo OL, Alaux-Cantin S, Hambucken A, Trifilieff P, Bontempi B. 2011. Early tagging of cortical networks is required for the formation of enduring associative memory. Science 331: 924-928.

McClelland JL, McNaughton BL, O'Reilly RC. 1995. Why there are complementary learning systems in the hippocampus and neocortex: insights from the successes and failures of connectionist models of learning and memory. Psychol Rev 102: 419-457.

Müller GE, Pilzecker A. 1900. Experimentelle beitrage zur lehre vom gedachtnis. Z Psychol 1: 1-300.

Nader K, Einarsson EO. 2010. Memory reconsolidation: An update. Ann NY Acad Sci 1191: $27-41$

Nader K, Hardt O. 2009. A single standard for memory: the case for reconsolidation. Nat Rev 10: 224-234.

Nader K, Schafe GE, Le Doux JE. 2000. Fear memories require protein synthesis in the amygdala for reconsolidation after retrieval. Nature 406: $722-726$.

Schacter DL, Addis DR. 2007. The cognitive neuroscience of constructive memory: remembering the past and imagining the future. Philos Trans $R$ Soc Lond B Biol Sci 362: 773-786.

Suzuki A, Josselyn SA, Frankland PW, Masushige S, Silva AJ, Kida S. 2004. Memory reconsolidation and extinction have distinct temporal and biochemical signatures. J Neurosci 24: 4787-4795.

Vetere G, Restivo L, Cole CJ, Ross PJ, Ammassari-Teule M, Josselyn SA, Frankland PW. 2011. Spine growth in the anterior cingulate cortex is necessary for the consolidation of contextual fear memory. Proc Natl Acad Sci 108: 8456-8460.

Wang SH, de Oliveira Alvares L, Nader K. 2009. Cellular and systems mechanisms of memory strength as a constraint on auditory fear reconsolidation. Nat Neurosci 12: 905-912.

Ward MT, Oler JA, Markus EJ. 1999. Hippocampal dysfunction during aging I: deficits in memory consolidation. Neurobiol Aging 20: 363-372.

Wiltgen BJ, Zhou M, Cai Y, Balaji J, Karlsson MG, Parivash SN, Li W, Silva AJ. 2010. The hippocampus plays a selective role in the retrieval of detailed contextual memories. Curr Biol 20: 1336-1344.

Zhao MG, Toyoda H, Lee YS, Wu LJ, Ko SW, Zhang XH, Jia Y, Shum F, Xu H, Li BM, et al. 2005. Roles of NMDA NR2B subtype receptor in prefrontal long-term potentiation and contextual fear memory. Neuron 47: $859-872$.

Received May 23, 2012; accepted in revised form June 29, 2012. 


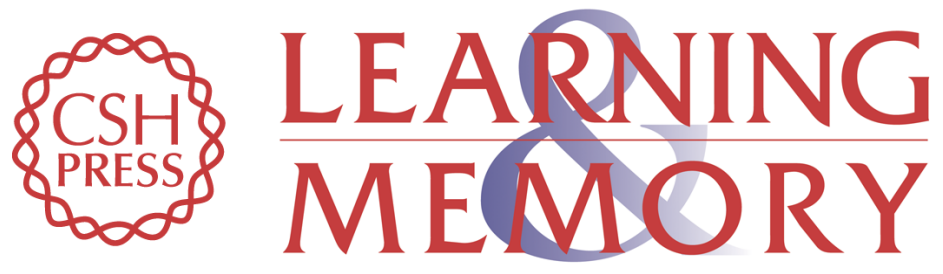

\section{Involvement of the anterior cingulate cortex in formation, consolidation, and reconsolidation of recent and remote contextual fear memory}

Einar Ö. Einarsson and Karim Nader

Learn. Mem. 2012, 19:

Access the most recent version at doi:10.1101//m.027227.112

Supplemental http://learnmem.cshlp.org/content/suppl/2012/09/07/19.10.449.DC1

Material

References This article cites 34 articles, 12 of which can be accessed free at: http://learnmem.cshlp.org/content/19/10/449.full.html\#ref-list-1

License

Email Alerting Receive free email alerts when new articles cite this article - sign up in the box at the Service top right corner of the article or click here. 